\title{
Beoordeling van studentgedrag: de ervaringen van tutoren
}

\author{
M. Penninga, J. Schönrock-Adema, J. Cohen-Schotanus
}

\section{Samenvatting}

Inleiding: Het doel van dit onderzoek was de ervaringen van tutoren met een gedragsbeoordelingslijst te inventariseren om deze beoordelingslijst verder te kunnen verbeteren. Tutoren hebben aan de hand van de beoordelingslijst de eerste- en tweedejaars studenten geneeskunde uit hun tutorgroep beoordeeld op professioneel gedrag. De beoordelingslijst omvatte drie dimensies: omgaan met werk en taken, omgaan met anderen en omgaan met eigen functioneren.

Methode: Alle tutoren van de in totaal 126 tutorgroepen kregen een vragenlijst toegestuurd over het gebruik van de beoordelingslijst. Hiervan zijn 44 (34,9\%) vragenlijsten ingevuld geretourneerd.

Resultaten: Tutoren achten zichzelf goed in staat individuele studenten te beoordelen, met name wanneer het gaat om de dimensies omgaan met werk en taken en omgaan met anderen. Wel ervaren ze overlap tussen deze twee dimensies. Tutoren vonden het moeilijker het omgaan met eigen functioneren te beoordelen.

Discussie en conclusie: De resultaten duiden er op dat tutoren met behulp van training beter op het beoordelen van gedrag voorbereid moeten worden. Daarnaast moet het omgaan met eigen functioneren concreter worden omschreven. (Penninga M, Schönrock-Adema J, Cohen-Schotanus J. Beoordeling van studentgedrag: de ervaringen van tutoren. Tijdschrift voor Medisch Onderwijs 2005;24(5):204-211.)

\section{Inleiding}

Dit onderzoek betreft de ervaringen van tutoren met het beoordelen van professioneel gedrag in tutorgroepen. Veel beroepsbeoefenaars werken in teamverband en daarvoor is een aantal professionele vaardigheden en een juiste, professionele instelling van belang.

Binnen het onderwijs was tot voor kort geen of weinig aandacht voor het beoordelen van deze professionele instelling. Binnen het medisch onderwijs is deze lacune inmiddels onderkend: een landelijk projectteam, het Projectteam Consilium Abeundi (PCA), heeft de aanbeveling gedaan om aan alle medische faculteiten een longitudinale beoordeling van professioneel gedrag in te voeren. Daarbij wordt veel waarde gehecht aan de terugkoppe- ling naar studenten. ${ }^{1}$ Gebleken is dat de beoordeling van professioneel gedrag twee voorwaarden stelt: 1) het onderwijs dient kleinschalig te zijn en 2) de beoordelaar dient de student meerdere keren te zien functioneren om een beoordeling mogelijk te maken. ${ }^{2}$

Bij het Universitair Medisch Centrum Groningen (UMCG) heeft men dit advies ter harte genomen en is men begonnen met de ontwikkeling en invoering van een systeem voor het beoordelen van professioneel gedrag. Het onderwijsconcept bij het UMCG voldoet aan beide voorwaarden voor het beoordelen van professioneel gedrag. Zo is een belangrijk deel van het onderwijs kleinschalig (voorwaarde 1): studenten werken in tutorgroepen van acht à tien studenten. Daarnaast komen deze 
kleine groepen regelmatig samen onder begeleiding van een tutor (voorwaarde 2). Gedurende ongeveer tien weken komen studenten twee keer per week bijeen. In de eerste bijeenkomst van elke week wordt gebrainstormd over vier opdrachten. Tussen de eerste en de tweede bijeenkomst werken studenten de opdrachten thuis uit. In de tweede bijeenkomst worden de uitwerkingen van deze opdrachten gepresenteerd. De tutoren die deze bijeenkomsten begeleiden, zijn afkomstig uit verschillende disciplines en wisselen in ervaring en inhoudsdeskundigheid (zowel artsen als niet-artsen). De tutoren vervullen vooral een rol als procesbewaker en worden inhoudelijk gesteund aan de hand van een tutorhandleiding. Alle tutoren hebben een training gehad in het begeleiden van een tutorgroep.

Conform de aanbevelingen in het rapport van het PCA is een beoordelingslijst voor het beoordelen van professioneel gedrag ontwikkeld. Deze beoordelingslijst is gebaseerd op de beoordelingslijst zoals deze in Maastricht wordt gebruikt. ${ }^{3}$ Daarbij worden drie dimensies van gedrag onderscheiden: omgaan met werk en taken, omgaan met anderen en omgaan met eigen functioneren (zie tabellen 1 en 2). De drie dimensies zijn omschreven met behulp van een aantal aandachtspunten. Per dimensie wordt gevraagd om een beoordeling in de vorm van een cijfer van 1 tot 10. Daarnaast is er bij elke dimensie ruimte om het cijfer toe te lichten met behulp van positieve punten en verbeterpunten voor de student. Met behulp van deze toelichting kan de student zijn gedrag gericht verbeteren. Omdat de tutoren de studenten regelmatig zien, werden zij gevraagd de studenten uit hun tutorgroep te beoordelen aan de hand van een beoordelingslijst. Om de gedragsbeoordeling te vergemakkelijken konden tutoren tijdens het trimester op een hulpformulier aantekeningen maken van het gedrag van de studenten. Om tutoren voor te bereiden op het beoordelen van gedrag vond voorafgaand een instructie plaats en ontvingen zij schriftelijke uitleg.

Eerder onderzoek heeft zich geconcentreerd op de psychometrische aspecten van het gebruikte beoordelingsinstrument. Dit onderzoek richt zich op de ervaringen van de beoordelaar met als doel het verbeteren van de beoordelingslijst en van het beoordelen van gedrag.

\section{Methode}

\section{Proefpersonen en procedure}

Alle tutoren uit het eerste en tweede trimester van jaar 1 en jaar 2 van de opleiding Geneeskunde zijn elektronisch benaderd met de vraag een bijgevoegde vragenlijst in te vullen. In totaal werden 126 vragenlijsten verstuurd.

\section{Instrument}

De vragenlijst bestaat uit vier vragen. Eerst wordt tutoren gevraagd of de omschrijvingen bij de beoordelingsdimensies op het invulformulier (de aandachtspunten onder omgaan met werk en taken, omgaan met anderen en omgaan met eigen functioneren) duidelijk waren (ja/nee). Wanneer het antwoord op de vraag 'nee' is, dient een toelichting te worden gegeven.

De tweede vraag betreft het inschatten van het gedragsniveau van de individuele student. Hierbij dienen tutoren per dimensie aan te geven hoe moeilijk het was individuele studenten op de betreffende dimensie te beoordelen (waarbij $1=$ makkelijk en $5=$ moeilijk) en wat het moeilijk of juist makkelijk maakte om een goede inschatting van het niveau van de student te maken. De derde vraag is een inventarisatie van aandachtspunten en gedragsaspecten die de tutor heeft gemist 
in de beoordelingslijst. Daarbij wordt gevraagd bij welke gedragsdimensie de eventuele gemiste punten passen of welke gedragsdimensie de tutor aan de lijst zou willen toevoegen. De vragenlijst wordt afgesloten met een open vraag naar suggesties ter verbetering en de mogelijkheid aanvullende opmerkingen te maken.

\section{Statistische analyse}

De gegevens over de verschillende dimensies van de beoordelingslijst zijn met elkaar vergeleken. Deze vergelijking is gemaakt met behulp van een paired sample t-test. Verder is getracht op basis van de antwoorden verbeterpunten te formuleren.

Tabel 1. Voorbeeld van een instrument voor de beoordeling van studentgedrag in de tutorgroep.

Naam student:

Studentnr:

Handtekening (voor gezien) student:
Naam tutor:

Trimester: Tutorgroep nr:

\section{Instructie}

Geef per dimensie (omgaan met werk, omgaan met anderen en eigen functioneren) eerst een schoolcijfer en geef daarbij een toelichting wat goed ging en wat beter kan. De aandachtspunten kunnen worden gebruikt als richtlijn bij de beoordeling (zie voor een toelichting bij de dimensies de achterzijde van dit formulier).

\begin{tabular}{|c|c|}
\hline $\begin{array}{l}\text { A Omgaan met werk/taken } \\
\text { Aandachtspunten: } \\
\text { voorbereiding } \\
\text { actieve houding/ inzet in de groep } \\
\text { feedback geven: inhoudelijk } \\
\text { rol vervullen/verantwoordelijkheid nemen } \\
\text { rapportage } \\
\text { inhoud } \\
\text { vorm }\end{array}$ & Toelichting (wat is goed, wat kan beter): \\
\hline $\begin{array}{l}\text { B Omgaan met anderen } \\
\text { Aandachtspunten: } \\
\text { samenwerking } \\
\text { actief luisteren } \\
\text { communicatie } \\
\text { stimuleert inbreng anderen } \\
\text { geeft op juiste manier feedback } \\
\text { afspraken nakomen \& op tijd komen }\end{array}$ & Toelichting (wat is goed, wat kan beter): \\
\hline \multirow[t]{2}{*}{$\begin{array}{l}\text { C Eigen functioneren } \\
\text { Aandachtspunten: } \\
\text { kritische reflectie op eigen functioneren } \\
\text { omgaan met kritiek } \\
\text { zelfontwikkeling }\end{array}$} & Toelichting (wat is goed, wat kan beter): \\
\hline & Cijfer: \\
\hline
\end{tabular}


Tabel 2. Toelichting bij de beoordelingslijst.

\section{A Omgaan met werk/taken}

\section{Aandachtspunten:}

- Voorbereiding

Student heeft alle taken goed voorbereid (voorzitter, notulist, rapporteur, groepslid).

- Actieve houding/inzet in de groep

Toont aandacht/interesse, ook non-verbaal, stelt vragen, geeft argumenten, is kritisch.

- Feedback geven: inhoudelijk

De feedback is kritisch en inhoudelijk correct.

- Rol vervullen/verantwoordelijkheden nemen

Voldoet aan verplichtingen die bij rol horen, noteert afspraken, houdt logboek bij (notulist); vat samen indien nodig (als gespreksleider of groepslid), maakt afspraken of neemt besluiten.

- Rapportage

Inhoud

- Patiëntrapportage: inhoud/omgang tussen docent \& patiënt/eigen indruk.

- Opdrachtrapportage: alle vragen behandeld.

Vorm

- Duidelijke structuur, goed/effectief gebruik audiovisuele middelen, geeft uitleg in eigen woorden, beantwoordt vragen.

\section{B Omgaan met anderen}

Aandachtspunten:

- Samenwerking

Doet mee, vertoont geen storend gedrag.

- Actief luisteren

Luistert naar anderen, laat anderen uitspreken, gaat in op datgene wat is gezegd.

- Communicatie

Communiceert op opbouwende manier met anderen, laat waarde gesprekspartner intact.

- Stimuleert participatie

Vraagt anderen naar hun mening, moedigt anderen non-verbaal aan.

- Geeft op juiste manier feedback

Feedback is concreet, toepasbaar, veilig/opbouwend en niet aanvallend en wordt volgens feedbackregels gegeven.

- Afspraken nakomen \& op tijd komen

Is betrouwbaar wat afspraken betreft, de student komt afspraken na die in de groep zijn gemaakt, komt op tijd bij groepsactiviteiten of meldt zich, indien verhinderd, tijdig af.

\section{Eigen functioneren}

Aandachtspunten:

- Kritische reflectie op eigen functioneren

Student kijkt kritisch naar eigen functioneren, heeft reëel zelfbeeld, is goed in staat eigen sterke en zwakke punten te benoemen/formuleert leerpunten.

- Omgaan met kritiek

Student staat open voor/toont begrip voor feedback van medestudenten/tutor, vraagt zonodig

toelichting.

- Zelfontwikkeling

Student probeert eigen functioneren te verbeteren evt. A.D.H.V. eerder geformuleerde leerpunten. 


\section{Resultaten}

Van de 126 verstuurde vragenlijsten zijn er 44 ingevuld geretourneerd (34,9\%); 24 vragenlijsten hadden betrekking op jaar 1 en 20 op jaar 2 .

\section{De gedragsdimensies}

De omschrijvingen (aandachtspunten) bij de verschillende dimensies werden in 79.5\% van de gevallen als duidelijk beoordeeld. Wanneer werd aangegeven dat de omschrijvingen niet duidelijk waren $(n=9)$ werd als reden aangegeven dat bepaalde aspecten uit de verschillende dimensies overlappen, met name bij omgaan met werk en taken en omgaan met anderen. Hierbij wordt bijvoorbeeld 'feedback geven' genoemd, wat deel uitmaakt van beide dimensies. Daarnaast vinden vier van de negen tutoren de laatste dimensie, omgaan met eigen functioneren onduidelijk.

\section{Het beoordelingsproces}

De tutoren vonden het gemiddeld genomen niet moeilijk studenten te beoordelen op omgaan met werk en taken (zie tabel 3). De meeste tutoren vonden deze dimensie concreet en daarom makkelijk te beoordelen $(n=26)$. Ook omgaan met anderen werd door het grootste gedeelte van de tutoren als makkelijk ervaren. Vijftien tutoren gaven aan deze dimensie ook concreet te vinden; acht tutoren vonden deze dimensie wel makkelijk, maar vager en subjectiever dan omgaan met werk en taken. Ook werd aangegeven dat er buiten de tutorgroep veel gebeurt dat te maken heeft met omgaan met anderen, wat de tutor niet ziet. Bovendien was het onderscheid met omgaan met werk en taken niet altijd duidelijk. Het kost tutoren meer tijd om tot een goede beoordeling van omgaan met anderen te komen. Tutoren vonden het omgaan met eigen functioneren het moeilijkste te beoordelen. Het beoordelen van het omgaan met eigen functioneren werd als significant moeilijker ervaren dan het beoordelen van het omgaan met werk en taken $(\mathrm{t}(44)=5.66, \mathrm{p}<.001)$ en omgaan met anderen $(\mathrm{t}(44)=4.12, \mathrm{p}<.001)$. Als reden hiervoor geven tutoren dat dit proces zich grotendeels afspeelt in de student zelf en daarom niet altijd voor de buitenwereld zichtbaar is, alleen in sommige extreme gevallen. Volgens sommige tutoren is deze dimensie alleen te beoordelen door te kijken naar de feedback die men zichzelf geeft en naar de reactie op de feedback die men krijgt. Vooral het aandachtspunt 'zelfontwikkeling' werd als moeilijk ervaren.

\section{Overige opmerkingen}

Negen tutoren misten één of meer onderdelen in de beoordelingslijst. Gemiste aspecten zijn de uitwerkingen van de opdrachten, het opzoeken van extra informatie buiten de leerstof om, het presenteren en hoe de student omgaat met problemen. Bij de opmerkingen werden uiteenlopende punten genoemd door 28 tutoren. Sommige tutoren hadden behoefte aan een vijf - of driepuntsschaal of aan een uitgebreidere instructie

Tabel 3. Antwoordverdeling in percentages, ${ }^{*}$ gemiddelden (M) en standaarddeviaties (SD) van de moeilijkheidsgraad van het beoordelen per dimensie.

\begin{tabular}{lccccc}
\hline Beoordeling & Makkelijk & Neutraal & Moeilijk & M & SD \\
\hline Omgaan met werk en taken & $69.2 \%$ & $15.4 \%$ & $15.3 \%$ & 2.2 & 1.1 \\
Omgaan met anderen & $42.3 \%$ & $34.6 \%$ & $23.1 \%$ & 2.8 & 1.0 \\
Omgaan met eigen functioneren & $19.6 \%$ & $15.7 \%$ & $64.7 \%$ & 3.6 & 1.1 \\
\hline
\end{tabular}

* 1 en $2=$ makkelijk; $3=$ neutraal; 4 en $5=$ moeilijk. 
over de dimensies en de aandachtspunten. Anderen gaven het advies consequenties aan de beoordeling te verbinden. Vijf tutoren gaven aan tevreden te zijn met de huidige beoordelingslijst. Verder werd opgemerkt dat de rol van de tutor verandert. Doordat de tutor nu ook gaat beoordelen, wordt de relatie tussen tutor en student aangetast. Overige opmerkingen betreffen de tijdsinvestering, welke enigszins tegenviel en de bespreking van de beoordeling met de studenten. De manier van bespreken wisselde per tutor, één tutor koos voor een plenaire bespreking, terwijl een andere tutor de oordelen juist per e-mail verstuurde.

\section{Discussie en conclusie}

De vraag in dit onderzoek was wat de ervaringen van tutoren waren met het gebruik van de huidige beoordelingslijst. Over het algemeen waren deze ervaringen positief. De omschrijvingen waren compleet en duidelijk en tutoren waren in staat hun studenten te beoordelen. Wel werd zo nu en dan overlap ervaren tussen dimensies en hadden tutoren moeite met het beoordelen van de laatste dimensie, omgaan met eigen functioneren.

De verschillende dimensies waren volgens de tutoren duidelijk. Toch ervoeren sommige tutoren overlap tussen bepaalde aspecten van omgaan met werk en taken en omgaan met anderen. Bij de constructie van de beoordelingslijst was het de bedoeling onderscheid tussen de dimensie te maken, maar blijkbaar was de kern van de verschillende gedragsdimensies en het onderscheid ertussen nog niet voldoende duidelijk voor de tutoren. Een eerste reden hiervoor kan gebrek aan ervaring met het beoordelen van gedrag zijn: de tutoren beoordeelden studenten ten tijde van dit onderzoek voor het eerst op professioneel gedrag. Cardy et al. concludeerden dat beoordelaars die meer ervaring hebben met het te beoordelen domein, bijvoorbeeld door vaker een beoordeling te hebben uitgevoerd, de beoordelingsdimensies beter konden inschatten en accurater beoordeelden. ${ }^{4}$ Een tweede reden kan zijn dat de voorbereiding op het beoordelen van gedrag niet voldoende was. Tutoren werden schriftelijk en mondeling geïnformeerd over het beoordelen van gedrag en de gedragsdimensies. Niet alle tutoren waren echter aanwezig tijdens de mondelinge toelichting.

Bij de implementatie van een nieuw beoordelingssysteem verdient het aanbeveling de beoordelaars goed op de hoogte te brengen van onder meer het doel van de beoordeling en van de beoordelingsprocedures. ${ }^{3}$ Training in het beoordelen van professioneel gedrag zou het begrip van de gedragsdimensies en van de beoordelingsprocedure kunnen verbeteren. Grunefeld beveelt het trainen van beoordelaars ook aan als oplossing voor weerstand tegen het beoordelen en voor negatieve effecten als te grote tijdsbelasting. ${ }^{5}$ Een effectief gebleken trainingsopzet is een opzet die aansluit bij de sociale leertheorie van Bandura. ${ }^{6}$ Essentieel hierbij is het leren van voorbeelden waarmee het cognitieve proces wordt gestuurd en vervolgens het zelf oefenen. Belangrijk is ook het geven van feedback, waarbij een positieve uitvoering wordt bekrachtigd. Woehr en Huffcutt beschrijven een training die positief effect heeft op de accuraatheid van beoordelingen. ${ }^{7}$ In deze training worden de verschillende dimensies waarop wordt beoordeeld toegelicht. Vervolgens worden voor elke dimensie voorbeelden besproken van incidenten die representatief zijn voor het beoordelen van een bepaalde dimensie. Ten slotte wordt geoefend met het beoordelen. Zij noemen dit een 'frameof-reference' training.

Tutoren waren over het algemeen in staat om hun studenten te beoordelen, met name op de dimensies omgaan met werk en 
taken en omgaan met anderen. Ze ervoeren de meeste moeilijkheden met het beoordelen van omgaan met eigen functioneren. Ze vinden dat deze gedragsdimensie minder concreet is dan omgaan met werk en taken en omgaan met anderen. De aspecten van omgaan met eigen functioneren vinden te veel impliciet plaats en zijn daarom moeilijker waarneembaar. Een manier om de bijbehorende gedragsaspecten meer te expliciteren is het vragen naar leerpunten voorafgaand aan een presentatie of een voorzitterschap. Door leerpunten van de vorige keer te laten expliciteren, kan de aandacht worden gericht op deze punten en op eventuele groei hierin. Het laten expliciteren van leerdoelen heeft nog een tweede positief effect. Het stimuleert de student om zijn/haar eigen leerproces te reguleren. Studenten die eigen doelen formuleren, zijn beter in staat hun leren efficiënt te plannen en in de gaten te houden. ${ }^{8}$

Een kanttekening bij dit onderzoek is de lage respons (35\%). Het is daarmee de vraag of de groep respondenten representatief is voor de gehele populatie. Wel is de verdeling over de studiejaren evenredig en komen de resultaten van dit onderzoek overeen met opmerkingen die tijdens plenaire bijeenkomsten zijn gemaakt. Verder is niet bekend hoe de groep respondenten is verdeeld op eigenschappen als ervaring met het tutorschap en inhoudsdeskundigheid. De invloed van deze kenmerken op de ervaring met het beoordelen van gedrag is dus niet aan te geven. Ondanks de geringe respons bieden de resultaten en de gemaakte opmerkingen voldoende aanknopingspunten om de beoordelingslijst en het beoordelen van gedrag te verbeteren.

Geconcludeerd kan worden dat tutoren, ondanks hun onervarenheid met het beoordelen van gedrag, goed in staat zijn om individuele studenten te beoordelen.
Dit geldt vooral wanneer het gaat om het beoordelen van het omgaan met werk en taken en het omgaan met anderen. De gedragsdimensie omgaan met eigen functioneren vonden de tutoren moeilijker om te beoordelen. Het beoordelingsproces kan worden verbeterd door de tutoren met behulp van een specifieke training voor te bereiden op het beoordelen.

Vervolgonderzoek zou zich kunnen richten op de kwaliteit van beoordelingen en op de effecten van training op de opvattingen van tutoren. Ook kan worden onderzocht of er verschillen zijn tussen ervaren en onervaren tutoren en artsen en niet-artsen.

\section{Literatuur}

1. Projectteam Consilium Abeundi. Professioneel gedrag. Onderwijs, toetsing, begeleiding en regelgeving. Utrecht: DMW, VSNU; 2002.

2. Luijk SJ van, Santen-Hoeufft M van, Schrander J. Relevante ervaringen met onderwijs en toetsing van professioneel gedrag. Tijdschrift voor Medisch Onderwijs 2003;22(3):128-38.

3. Luijk SJ van, Santen-Hoeufft M van, Hillen HFP, Smeets JGE. Het beoordelen van professioneel gedrag bij studenten en artsen. Tijdschrift voor Medisch Onderwijs 2000;19(5):163-71.

4. Cardy RL, Bernardin HJ, Abbott JG, Senderak MP, Taylor K. The effects of individual performance schemata and dimension familiarization on rating accuracy. Journal of Occupational Psychology 1987;60:197-205.

5. Grunefeld H. Toetsinstrumenten voor kerncompetenties in projectonderwijs. Tijdschrift voor Hoger Onderwijs 2001;44:44-54.

6. Bandura A. Social foundations of thought and action. Englewood Cliffs, NJ: Prentice-Hall; 1986.

7. Woehr DJ, Huffcutt AI. Rater training for performance appraisal: A quantitative review. Journal of Occupational and Organizational Psychology 1994;67:189-205.

8. Azevedo R, Ragan S, Cromley JG, Pritchett S. Do different goal-setting conditions facilitate students' ability to regulate their learning of complex science topics with RiverWeb? [paper op internet]. Annual Meeting of the American Educational Research Association; 21-25 april 2003; Chicago, IL, United States [cited 25 mei 2005]. Beschikbaar op: http://www.eric.ed.gov/contentdelivery/servlet/ ERICServlet?accno=ED482509. 


\section{De auteurs:}

Mw. drs. M. Penninga is werkzaam bij het Onderwijsinstituut, afdeling Docentondersteuning en Kwaliteitszorg van de Rijksuniversiteit Groningen en het Universitair Medisch Centrum Groningen.

Mw. dr. J. Schönrock-Adema is werkzaam bij de afdeling Innovatie en Onderzoek Medisch Onderwijs van de Rijksuniversiteit Groningen en het Universitair Medisch Centrum Groningen.

Mw. dr. J. Cohen-Schotanus is hoofd van de afdeling Innovatie en Onderzoek Medisch Onderwijs van de Rijksuniversiteit Groningen en het Universitair Medisch Centrum Groningen.
Correspondentieadres:

Mw. drs. M. Penninga, Onderwijsinstituut, afdeling Docentondersteuning en Kwaliteitszorg van de Rijksuniversiteit Groningen en het Universitair Medisch Centrum Groningen, A. Deusinglaan 1, 9713 AV Groningen, tel.: 050-3638378, fax: 050-3633865, m.penninga@med. rug.nl.

\section{Summary}

Introduction: We examined tutors' experiences with an instrument for assessing medical students' professional behaviour in order to improve this instrument. All the tutors of the undergraduate tutor groups in Years 1 and 2 used the instrument to assess the professional behaviour of the students in their groups. The instrument asks the tutors to give an assessment of students' professional behaviour on three dimensions: i.e. dealing with work and tasks, dealing with others, and dealing with one's personal functioning.

Method: All the tutors of the total of 126 tutor groups were asked to complete a questionnaire about the use of the assessment instrument. A total of 44 completed questionnaires were returned (34.9\%).

Results: The tutors indicated that they considered themselves fully capable of assessing individual students' professional behaviour, in particular with respect to the dimensions dealing with work and tasks and dealing with others. They did indicate, however, that these dimensions showed some overlap. The tutors reported having greater difficulty assessing the way students dealt with personal functioning.

Discussion and conclusion: The results suggest that tutors would benefit from training to prepare them for assessing students' professional behaviour. Improvement can also be achieved by re-writing the part of the instrument related to personal functioning in more concrete terms. (Penninga M, Schönrock-Adema J, Cohen-Schotanus J. Assessing students' professional behaviour: tutors' experiences. Dutch Journal of Medical Education 2005;24(5):204-211.) 